\title{
THE ROLE OF MEDIA IN CREATING AWARENESS ON CHILD SEXUAL ABUSE AMONG SCHOOL STUDENTS
}

\author{
ARCHANA SHARMA \\ Faculty of Mass Communication, \\ Department of Mass Communication and Media Technology, \\ RIMT University \\ Delhi-Jalandhar GT Road (NH1), Sirhind Side, \\ Mandi Gobindgarh, Punjab, India \\ E-mail address: archanasharma@rimt.ac.in \\ ORCID: https://orcid.org/0000-0001-6575-9761
}

\begin{abstract}
Aim. This study aims to analyse the role of media in creating awareness on child sexual abuse and Good Touch Bad Touch among children. The research also aims to study the students' awareness level of Child Sexual Abuse which includes the Good Touch Bad Touch.

Method. The survey research method was used to collect data, through a well-structured questionnaire from 100 respondents of a school from a city of Punjab, constituting 20 respondents from each class, selected through convenient sampling.

Result. The findings reveal that the media failed to create awareness on child sexual abuse among children. $90 \%$ of the respondents were not aware of any child sexual abuse or child helpline number.

Conclusion. Even though, some initiatives were taken by various media tools to raise the child safety issue in the society, but those are not enough. There is a need to develop and run more specific programs regularly to raise awareness throughout society on child sexual abuse.

Key words: Role of media, child sexual abuse, good touch bad touch, school stu-
\end{abstract} dents, awareness

\section{INTRODUCTION}

Children are considered to be the backbone of a country. It is the right of every child to spend its childhood in a happy and safe environment. Therefore, it is necessary to provide a healthy, protective, and positive environment to children for their overall growth. Child sexual abuse (CSA) is of worldwide concern, causing psychological and physical health issues among children including depression, unwanted pregnancy, and many more. CSA is harmful to 
the normal growth of a child. The sexually abused child has to face the problems of aggression, depression, genital infection, unwanted pregnancy, HIV, etc. Even abused children have not been given any protection and psychological therapeutic assistance.

India is facing a steady rise in cases of child molestation, rape, and sexual abuse due to the absence of adequate knowledge on this particular issue. India is ranked the second-largest child population in the world. When we talk about the safest country for children then, India was $65^{\text {th }}$ rank among 80 countries in 2019 (The Print Team, 2019). The cases of crimes against children cover child molestation, child labour, rape, sexual assault, physical and mental harassment which are increasing day by day in all sections and community groups. In spite of child safety being of utmost importance, the talks and debates on sexual abuse are still prohibited in India due to its cultural and social resistance. The abused children are continually being neglected by the family and society due to a lack of awareness on the issues.

According to the BBC report (2017), a child is sexually abused every 15 minutes in India (BBC News, 2017). NCRB report (2018), shows that 21,605 of child rape cases were recorded in 2018 including 21,401 girl child rape and 204 boy child rape cases. The report claimed that 109 children were sexually abused every day in India (Sengupta, 2020).

Table 1

Cases of sexual violence against children reported under The Protection of Children from Sexual Offences (POCSO) Act in 2018 (Girl Child Victim Only)

\begin{tabular}{llc} 
& Sexual violence cases & Growth \\
\hline Sr. No. & Child Rape & 21,401 \\
2 & Sexual Assault & 14,124 \\
3 & Sexual Harassment & 1,651 \\
4 & Child Pornography & 790 \\
5 & Unnatural Sex & 41 \\
6 & Other Offences & 819 \\
\hline
\end{tabular}

Source: own study based on NCRB Report, 2018.

The magnitude of such cases against children can be seen from Table 1 . The statistics show that in 2018, there were 21,401 cases of girl child rape, 14124 cases of sexual assault to girls, 1651 cases of sexual harassment against girls, 790 girl child pornography cases and 41 cases of unnatural sex was reported under the Protection of Children from Sexual Offences (POCSO) Act (Gautam, 2020).

The global compilation of reports of child sexual abuse material ranked India in the top list among the countries where CSA material uploaded online is reported in a high ratio (Ramya, 2020). The safety of children is becoming a major problem in Indian society and this is a matter of grave concern. Many studies and facts prove that in the majority of cases family friends, relatives, 
and neighbours are involved in this heinous crime. Still, parents and teachers are reluctant to come forward to discuss this issue with children. This silence and negligence over the issue are encouraging the criminals to target children of the youngest age group.

It is high time to attend to the need for safety of children against sexual and other crimes. Many children fail to understand that they are being sexually abused in the absence of proper knowledge. Those who understand what happened to them, are not willing to share it with their parents due to certain reasons. They do not want to share what they experienced because of shame, social stigma, or for fear of being scolded by parents. Some of the parents, having been informed that their children were the victims of sexual abuse, impose unnecessary restrictions on them that further lead to children not discussing anything related to this with them. They are even not aware of the child helpline number and laws related to their safety.

In this background, it is felt that the government and people should give their support and take initiative to make society aware of the importance of basic sex education at the school level. Parents should come forward to talk about the issue with their children by winning their confidence, giving suitable examples, sharing stories and trying other methods. According to a news in Times of India, during the lockdown period, as a result of Covid-19 in India, children have shared sexual abuse incidents with their parents (Tom, 2020).

\section{CHILD SEXUAL ABUSE: CONCEPTUAL FRAMEWORK}

Child sexual abuse is a universal problem with life-long traumatic grief and guilt. Sexual abuse means any sexual conduct upon a child undertaken by an adult or older person for satisfying the sexual desires of the perpetrators. The United Nations International Children's Fund defines CSA as:

Contacts or interactions between a child and an older or more knowledgeable child or adult (a stranger, sibling or person in a position of authority, such as a parent or caretaker) are when the child is being used as an object of gratification for the older child's or adult's sexual needs. These contacts or interactions are carried out against the child using force, trickery, bribes, threats or pressure (UNICEF, 2013, p. 16).

POCSO Act describes the various forms of sexual abuse which happen to children including Physical and Non-physical sexual assault. A physical contact is a form of abuse that includes physical contact between the offender and the child, such as penetrative sex, fondling of the child's genitals or making the child touch the offender's genitals, touching any part of the child's body with sexual intent, forcing or persuading a child to engage in any type of sexual act like kissing etc.

Non Physical contact includes showing pornographic videos or pictures to a child, verbal abuse, making lewd gestures to a child, playing sexualised games, stalking the child or chatting with sexual intent with the child over the internet, etc. (National Commission for Protection of Child Rights, 2017). 


\section{LACK OF AWARENESS}

There is a general lack of awareness among children regarding sexual abuse. Even children of 10 to 16 years are not able to understand the meaning of the phrase CSA. Many of them relate CSA to rape only. Children do not share the incidents of sexual abuse with their family members because of the communication gap between children and parents. In some cases, children informed their parents about the abuse, but parents suggested to keep silent due to the fear of dishonour and social stigma.

There is an immediate need to bring a change in the attitude of society towards sex education. The Government should run special campaigns to educate everyone in society about the importance of child safety. For example, the government is running a special awareness and prevention campaign on Covid-19 virus. Special messages are being printed in the newspapers and broadcast through electronic media for all age group audiences. This type of campaign should be run through different communication channels to change the attitude of society towards the importance of child safety.

\section{MEDIA INITIATIVES: AN ASSESSMENT}

Media reaches the majority of the population of the country, it is the main source of information for people. Media plays a significant role in forming and influencing people's attitudes and behaviour. It is the only common platform through which impactful and meaningful messages can be delivered to a large group of society. Media's role is not only to create information, to cover and report the crime news against children, they should also produce special informative programs on the issue of child safety. Some tools of media have tried to inform society about child sexual abuse and laws made for child safety in India. Researchers will discuss the contribution of the mass media in raising the child safety issue in India.

\section{PRINT MEDIA}

The print media is the key disseminator of information in every society. Large numbers of the population depend on newspapers and magazines for information and facts related to any topic. Media and News reports can influence public opinion at large.

Newspapers In Education (NIE), the program was designed in America to encourage students to help them in developing analytical thinking over the current events around the world. In India newspapers like Hindustan Times, Times of India and Pioneer are running an NIE program through their special supplements for students. Some newspapers are also running online NIE programmes for school students through their websites to facilitate students in sharing their valuable thoughts over national and international issues (The Hindu, 2011). 


\section{RADIO}

According to Nielsen Report 2018, radio is the second most accessed media in India with $86 \%$ of users in cities. The radio has the special feature to overcome the barriers of illiteracy and distance. This specialty help radio services to reach a large group of people in India (Ahluwalia, 2018).

AIR and Private FM have taken some initiatives to impart knowledge about Children's Rights and Child sexual abuse in the society through their various stations. AIR, FM Rainbow, Vividh Bharati and other private FM channels of Delhi aired special radio spots and campaigns related to POCSO Act and child safety in NCR area (Ministry of Women and Child Development, 2016-17). But all these programs were broadcast only for a duration of one week. Now the current situation demands to run such programs on a regular basis.

\section{TELEVISION}

Television is an extensively used media in the modern lifestyle. Television is the most favourite childrens' medium in India. However, the researchers have not found any special TV program based on children's rights, Good Touch Bad Touch (GTBT) and child sexual abuse. The content related to child sexual abuse was shown only in crime based TV programs and news channels. Only one or two TV serials talked about children's rights but that content was not enough to raise the awareness on issues related to sexual abuse and POSCO Act.

\section{SOCIAL MEDIA}

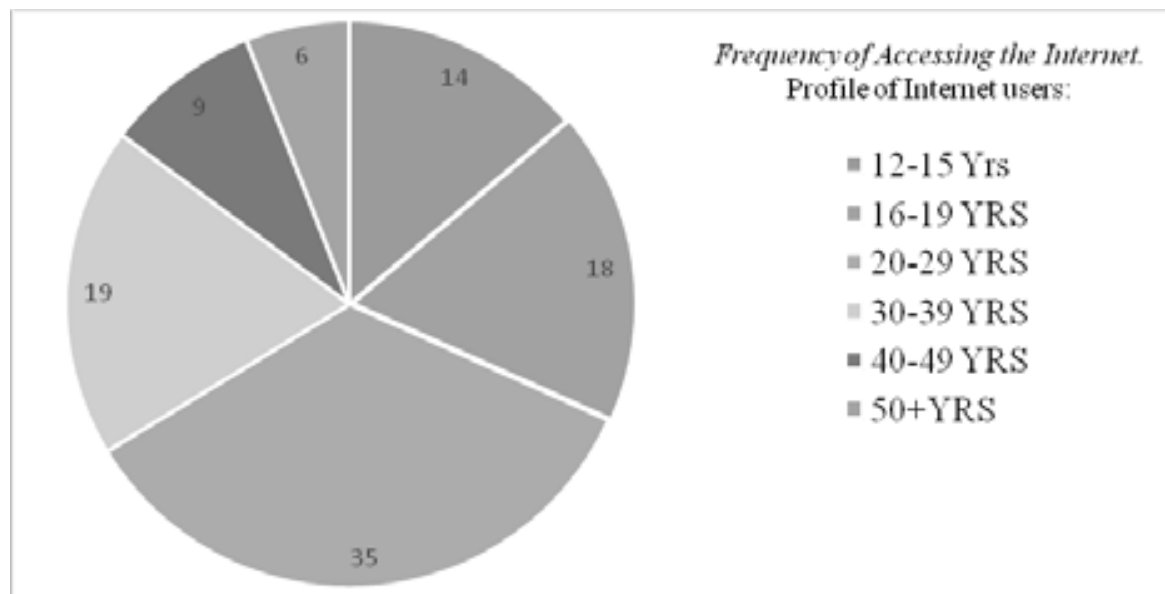

Fig. 1. This figure demonstrates the Internet users divided by age group in India till 31 march, 2019. Distribution of internet users by age group in \%. Source: own study based on Nielsen and Internet and Mobile Association of India Report (2019). 
According to the Nielsen and Internet and Mobile Association of India Report (2019), India accounted for 451 million active internet users till March 31, 2019. From the overall Internet users, $66 \mathrm{Mn}$ users are of 5 to 11 years of age group (India Internet 2019, 2019). So this medium can also be used positively to educate students about CSA. Some Non-Governmental Organizations (NGOs) and the Indian Government are already using different social media like YouTube, Facebook, WhatsApp, Instagram, etc. to create awareness about child sexual abuse. The SCPCR in the Andaman Islands has made 30-40 small videos for the Whatsapp platform on children's rights (National Workshop on Protection of Child Rights, 2016).

One NGO AWARE is using a Mobile App Sarahah to motivate sexually abused children to share their experience with them through this App (Parab, 2017). Similarly, Me Too was an experiment to share the child sexual abuse cases in 2018 in the USA, and they witnessed positive results of this campaign as $42.2 \%$ of women in the USA admitted that they had faced sexual abuse before the age of 18 (Agathis, Payne, \& Raphael, 2018). One website Parentune gives ideas to parents to educate their children about the good touch and bad touch (India.com, 2018). These campaigns and movements can reach only the urban-oriented, well-settled adults, but the rural population is remaining untouched by these campaigns due to the unavailability of this mass medium.

\section{CINEMA}

Cinema is the most popular medium among Indian audiences. India is the largest producer of movies in the world. Therefore, movies can also become an interesting medium to convey the message of child safety in society. Some Bollywood movies: Ribbon, I am, Jaago, Page3, Highway, Monsoon Wedding, Kahaani 2, Udne Do, etc. also tried to raise the issue of child safety in society through entertainment content. National Council of Educational Research and Training (NCERT) suggested to teachers to show the national award-winning animated film Komal in their school to give knowledge about Good Touch Bad Touch to their students (Ganjapure, 2018).

Mass media education and prevention campaigns present a viable means for governments to do something about the problem of child sexual abuse and Good Touch Bad Touch. Mass media should design special education and prevention campaigns about child sexual abuse for children and young people. Newspapers can use their special supplements to provide information about CSA and GTBT to school students. These programs and campaigns should provide them useful information about the serious consequences of sexual abuse.

\section{LITERATURE REVIEW}

The subject of child sexual abuse is still a taboo in India. The silence in relation to the subject is becoming a barrier to creating awareness about it in India. 
There are very few studies conducted in India on child sexual abuse. These studies did not include a semi-rural and rural parts of the country. The studies on the media's role towards the issue are less discussed and reported.

Communication research experiments in the field of social and national development have been accompanied by the help of mass media in many developing and developed countries. Wilbur Schramm (1964) has explained in his book Mass Media and National Development, how information provided by mass media helped in preparing communities to accept the new changes and culture for their social development (Schramm, 1964).

Some research studies have been conducted on the media's responsibilities and their role in the issue. Jenny Kitzinger and Paula Skidmore (1995) researched on "One research study Playing Safe: The media coverage of CSA prevention strategies." They emphasise the role of media to promote mass media discussion on the prevention of CSA. The study explains how the media representation of child abuse cases is important as it creates a public attitude to formulate and implement child protection policies. Media not only focused on the news coverage but also publishing special articles, features, and stories about child sexual abuse. This education and awareness campaign launched by mass media has played an important role in placing the issue of child safety on the public and political agenda.

One of the first books on CSA Bitter Chocolate: Child sexual abuse, was written by Pinki Virani (2000). As a journalist and human rights activist, she has discussed the real-life stories of the victims of sexual abuse and problems faced by them in getting justice and surviving in society. The author has also pointed out how media are portraying children in advertisements and other programs. She has suggested how media should play a positive role to educate and inform the common public about the seriousness of the issue. She has also urged that there is a need for parents and children to talk on good touch and bad touch because most of the abusers are those who are trusted by children (Virani, 2000).

Chris Goddard and Bernadette J. Saunders (2001), highlighted the essential role of the media in increasing society's awareness of child abuse and neglect in their research paper "Child abuse and the Media." They examined the influence of television series, documentaries, and live theatre productions on the public. They suggested that the media played a significant role in forming and influencing people's attitudes and behaviour towards the issue. Selva Kumar (2011), conducted his Ph.D. in 2011 on the topic, Child Sexual Abuse: A Comparative Study of Schools in Urban and Rural Areas in Tamil Nadu on 1500 students. The main focus was to study the various forms of child sexual abuse prevalent in urban and rural areas in Tamil Nadu. The result shows that $37.2 \%$ of respondents have reported incidents of sexual abuse. The study also found that urban students were abused more frequently $(20.8 \%)$, as compared to the rural students (16.4\%).

Jane Long Weatherred (2015) analyses the media coverage of child sexual abuse cases over the past 50 years in the USA. His research study "Child Sexual 
Abuse and the Media: A Literature Review," focused on the importance of media in creating awareness. Parents admitted that they got the information related to CSA through media. The researcher suggested the importance of public communication to bring changes in the society for health improvement. Similarly, to study the importance of newspapers in educated children, Manojkumar Nagasampige and Kavita M. Nagasampige (2016) conducted a research on "Effectiveness of newspaper in education (NIE) programmes on the student performance." NIE a globally recognised program helps to connect the younger generation to current affairs and to improve the reading, writing, and thinking skills of students. The researcher urged that this is an interactive program to inform students about various topics (Nagasampige \& Nagasampige, 2016). Another researcher Hayam Qayyum (2018) analyses the media coverage and awareness campaign on child sexual abuse. His study "Media Coverage on Child Sexual Abuse in Developing Countries," proved that the media campaigns used to influence people's attitude towards the issue of child safety, successfully motivate them to give their contribution to solving the problem.

Most of the research studies, articles discussed the problem of the failure of proper communication between the teacher, students, and parents on the sex education. Some studies quoted the importance and role of media in running awareness campaigns related to the issue. Scholars gave examples of many countries where the media had run successful and impactful social campaigns on child sexual abuse. Although sexual abuse has become a major problem in all communities, especially among children below 10 years of age, the facts have not been explored in society. There is very little research work and books available in India related to the problem. The first-ever survey at the national level related to CSA was carried out in 2007 by The Ministry of Women and Child Welfare to understand the degree of child abuse in India. It was the only study conducted by the government at the national level. Some NGOs or other organisations have done some work in this field, but that was limited to one area or to the reported cases under POCSO Act. The researcher has not found any particular study that is based on the contribution of media in informing society about child safety or CSA.

\section{RESEARCH METHODOLOGY}

A descriptive study was carried out with the specific objective to study the role of media in creating awareness about CSA among children. The general objectives are to find out the source of information among students about CSA including GTBT and to investigate the nature of the problem of different forms of CSA faced by children.

The study was conducted in a government-aided school in Punjab, India. The study includes both, primary and secondary data. For primary data, 
Survey has been conducted with a sample of 100 students from a School at Mandi Gobindgarh city, Punjab. Respondents were selected from class 6th to 10th (20 students from each class) in the same ratio boys $(n=10)$ and girls $(n=10)$ through convenient sampling method. The secondary data has been collected from various researches, Government reports, newspapers, and NGO's data.

A self-administered questionnaire schedule was developed to collect data on the basis of the objectives of the study. It consists of two parts with total 29 questions. Part I consists of questions related to information about demographics and the media habits of the respondents and Part II consists of questions related to awareness on sexual abuse along with 5 questions regarding the experience of sexual abuse. Content validity of the questionnaire was ascertained by consultation with school teachers, counsellors, research advisors, and subject experts. The objectives of the study were clearly stated and explained to each respondent. They were clearly told about their voluntary participation in the study. All the questionnaires were filled through face to face interview method of each respondent.

\section{RESULTS AND DISCUSSION}

Research studies related to television viewing habits of children showed that television is the favourite medium among children. The present study supports the same notion. Table 2 describes the Media habits of the respondents; it shows that all the respondents like to watch television.

Table 2

Distribution of respondents by their media habits

\begin{tabular}{llcc} 
Sr. No. & Media Preferred & Number $(n)$ & Percentage (\%) \\
\hline $\mathbf{1}$ & TV & 100 & 100 \\
$\mathbf{2}$ & Radio & 42 & 42 \\
$\mathbf{3}$ & Newspaper & 61 & 61 \\
$\mathbf{4}$ & Internet/Social Media & 92 & 92 \\
\hline
\end{tabular}

Note: total respondents $=100$

Source: own research.

Radio is developing special education programs for children, but it is not so popular medium among respondents. They even didn't have any information about these programs. The above table enumerates that $42 \%$ of respondents listen to the radio. Out of them, only $26 \%$ listen to the radio regularly. Newspapers are encouraging students to develop their analytical thinking through their NIE programs. The above table shows that newspapers got $3^{\text {rd }}$ rank by respondents as their favourite medium. $61 \%$ of respondents read newspapers, but not on a regular basis. As compare to the radio, respondents prefer newspapers to get information on various topics. 
Journal of Education Culture and Society No. 2_2020

Nielsen Report (2019) states that in India 5 to 11 age group children contribute 66 million Internet users (Inc 42 2019). The current study supports the results of the above-mentioned report. After television, the Internet becomes the second-highest accessed medium by $92 \%$ of respondents.

Table 3

Distribution of respondents by television watching habits

\begin{tabular}{llcc} 
Sr. No. & Preferred TV Programs & Number $(n)$ & Percentage $(\%)$ \\
\hline $\mathbf{1}$ & TV Serial & 34 & 34 \\
$\mathbf{2}$ & Cartoons & 52 & 52 \\
$\mathbf{3}$ & Movies & 74 & 74 \\
$\mathbf{4}$ & Advertisement & 6 & 6 \\
$\mathbf{5}$ & News & 28 & 28 \\
$\mathbf{6}$ & Video Songs & 74 & 74 \\
$\mathbf{7}$ & Discovery/Animal Planet & 30 & 30 \\
$\mathbf{8}$ & Art and craft & 26 & 26 \\
\hline
\end{tabular}

Note: total respondents $=100$

Source: own research.

It is generally assumed that children like to watch cartoon programs on television. But data in Table 3 shows that the most favourite programs among respondents are movies and video songs. A high percentage (74\%) of respondents liked to watch movies and video songs on television. Cartoons were chosen by $52 \%$ of respondents. $34 \%$ of respondents marked daily soaps and reality shows as their favourite programs. As compared to entertainment, informative programs were liked by fewer respondents.

Table 4

Distribution of respondents by Radio listening habits

\begin{tabular}{llll} 
Sr. No. & Preferred Radio Programs & Number $(n)$ & Percentage $(\%)$ \\
\hline 1 & Songs & 34 & 81 \\
2 & News & 8 & 19 \\
3 & Special Talk & 2 & 5 \\
4 & General Knowledge & 2 & 5 \\
\hline
\end{tabular}

Note: total respondents $=42$

Source: own research.

The respondents were asked to express their preferences concerning various radio programs. Table 4 indicates that the maximum number of respondents use radio only for entertainment purposes. $81 \%$ of respondents like to listen to songs on the radio. Only 19\% of respondents mention that they listen to news programs on the radio, but again not regularly. 
Table 5

Distribution of respondents by Newspaper reading habits

\begin{tabular}{llcc} 
Sr. No. & Preferred N.P. Content & Number $(n)$ & Percentage (\%) \\
\hline 1 & Political News & 6 & 10 \\
2 & Crime News & 24 & 39 \\
3 & Sports News & 52 & 85 \\
4 & Educational News & 18 & 30 \\
5 & General News & 10 & 16 \\
6 & Entertainment News & 26 & 43 \\
7 & Article/Feature & 2 & 3 \\
8 & Special supplement & - & - \\
9 & Editorial & 2 & 3 \\
10 & Any Other & - & - \\
\hline
\end{tabular}

Note: total respondents $=61$

Source: own research.

Table 5 enumerates the content read by the respondents in a newspaper. Sports news gets the highest percentage. $85 \%$ of respondents give preference sports news in newspapers while $43 \%$ of respondents liked to read to Entertainment news. 39\% read crime-related news and 30\% of respondents read educational content in newspapers. Some newspapers are publishing special supplements with educational content but only $3 \%$ of respondents read special supplements of newspapers.

Table 6

Distribution of respondents by Internet habits

\begin{tabular}{llcc} 
Sr. No. & Preferred Content on Internet & Number $(n)$ & Percentage $(\%)$ \\
\hline 1 & Educational Assignment & 32 & 34 \\
2 & Games & 68 & 74 \\
3 & Movie & 36 & 39 \\
4 & Cartoons & 18 & 20 \\
5 & News & 14 & 15 \\
6 & Video Songs & 52 & 57 \\
7 & Social Media & 38 & 41 \\
8 & Any Other (TV serial and & 4 & 4 \\
\hline
\end{tabular}

Note: total respondents $=92$

Source: own research.

Nowadays children have more access to the internet and social media. $92 \%$ of respondents use the Internet for different purposes. The present study reveals that the internet is the most popular media among the respondents for entertainment and information.

When respondents were asked to mention their purpose of using the internet and social media, it was found that a majority of respondents $(74 \%)$ prefer- 
red playing games on the internet whereas $57 \%$ respondents use the internet to watch video songs. Table 6 shows social media that $57 \%$ respondents use the internet to watch video songs and $41 \%$ of respondents use the internet for WhatsApp, Instagram, TikTok, etc, and only 39\% use the internet for educational purposes.

Table 7

Awareness about GTBT, CSA, POCSO Act and Child Helpline Number

\begin{tabular}{llcc} 
Sr. No. & Knowledge on Topic & Number $(n)$ & Percentage (\%) \\
\hline 1 & Good Touch Bad Touch & 94 & 94 \\
2 & Child Sexual Abuse & 56 & 56 \\
3 & POCSO Act & 8 & 8 \\
4 & Child Helpline no & 1 & 1 \\
\hline
\end{tabular}

Note: total respondents $=100$

Source: own research.

When the researcher asked respondents about GTBT, 94\% of respondents were aware of GTBT. But they were not clear about the term "Good Touch Bad Touch" and they were not able to describe the term properly. When the researcher gave them some options of good touch and bad touch then they responded correctly. After being asked about the respondent's knowledge about child sexual abuse, only $56 \%$ of respondents knew about CSA. But they were not able to explain the various forms of CSA. Their understanding of the CSA was limited only to child rape and Bad Touch to a child.

The POCSO Act was enacted in 2012 to protect children from sexual abuse. NCERT also gave information about POCSO Act and the child helpline number on the back page of the syllabus book from class $6^{\text {th }}$ onwards, but the study revealed that only $8 \%$ respondents knew about POCSO, and they also didn't have full information about the ACT and its benefits to a child. Children and women helpline numbers have been displayed in every school, buses, and other public places but still, only one respondent knew the correct number of the child helpline. $12 \%$ respondents claimed to know the Child Helpline Number. But only one respondent gave the correct number of child helpline number 1098 while other respondents mentioned number 100 as the child helpline number.

The study reveals that television is the main source of information of $40 \%$ of respondents to get knowledge about GTBT. When respondents were asked to mention the program, content, and method through which they derived information about GTBT, the respondents told that they get an idea about the difference between good touch and bad touch through the rape scenes, rape news, or rape stories, they saw on television, movies and social media. However, they failed to recall any specific program related to the topic. 
Table 8

Source of information about GTBT and CSA

\begin{tabular}{llcccc} 
Sr. No. & Source of Information & GTBT $(n)$ & Percentage $(\%)$ & CSA $(n)$ & Percentage $(\%)$ \\
\hline 1 & Newspaper & 32 & 32 & 22 & 22 \\
2 & Television & 40 & 40 & 36 & 36 \\
3 & Radio & 2 & 2 & 2 & 2 \\
4 & Movie & 10 & 10 & 8 & 8 \\
5 & Internet & 20 & 20 & 16 & 16 \\
6 & Social Media & 12 & 12 & 8 & 8 \\
7 & Book & 8 & 8 & 6 & 6 \\
8 & Teachers & 26 & 26 & 10 & 10 \\
9 & Parents & 38 & 38 & 22 & 22 \\
10 & Peer Group & 16 & 16 & 6 & 6 \\
11 & Grandparents & 16 & 16 & 4 & 4 \\
12 & Neighbour & 2 & 2 & 2 & 2 \\
13 & Doctor & 4 & 4 & 2 & 2 \\
14 & Other Sources & - & & - & \\
\hline
\end{tabular}

Note: total respondents $=100$

Source: own research.

In India parents refrain from openly discussing topics such as sex with their children as Table 8 shows, only $38 \%$ of the respondents accept that they get knowledge on GTBT from their parents. 32\% marked the newspapers as their source of information. But again, they mentioned some crime news stories in response. In school, counsellors are appointed to impart knowledge on GTBT and sexual abuse to students. But here only $26 \%$ of respondents admit that teachers inform them about the GTBT.

Table 8 analyses the relative importance of different sources in creating awareness about CSA among the respondents. $36 \%$ of respondents gave the first rank to television as the main source of their information about CSA, but again they mentioned the crime scene in movies and crime based serials as their source of information. $22 \%$ of respondents said that they had read news related to child rape in newspapers and they relate it to CSA.

As compare to Good Touch Bad Touch fewer parents communicate with their children about sexual abuse. Only $22 \%$ of respondents got information about CSA from their parents. It was noticed that teachers also feel hesitant to initiate a healthy discussion on such topics with students in the classroom. As compared to GTBT, only $10 \%$ of teachers discussed topics related to sexual abuse with their students. Due to this communication gap, respondents do not have satisfactory knowledge of sexual abuse. 
Table 9

Personal experience of any form of CSA

\begin{tabular}{llcc} 
Sr. No. & Topic & Number $(n)$ & Percentage $(\%)$ \\
\hline 1 & Yes & 8 & 8 \\
2 & No & 74 & 74 \\
3 & Do not want to share & 18 & 18
\end{tabular}

Note: total respondents $=100$

Source: own research.

The researcher inquired about the percentage of respondents who have faced any form of CSA. Keeping in mind the sensitivity of the topic, five indirect questions were included in the questionnaire. While responding to these questions, total $26 \%$ of respondents admitted that they have faced one or another form of CSA. Table 9 shows that only $8 \%$ of respondents were ready to share the details of the incident with the researcher. Another $18 \%$ of respondents choose the given option, "doesn't want to share" their experience with us.

The study revealed that victims of all age groups hesitate in sharing their experiences related to sexual abuse. Those who shared their experience mentioned that their family, relatives and well-known people did this kind of activity with them. Some of them have faced other forms of abuse like touching of body parts in market places. Respondents belonging to the lower class shared their experience during the personal interview but higher class respondents did not share any such experience.

\section{CONCLUSION}

This study concludes that school children have inadequate knowledge about CSA and GTBT. Children as well as teachers were not comfortable talking about the issue. The result showed that although children have full access to media, they are still not fully aware of their safety rights, POCSO Act, and child helpline number. The media failed to create the desired level of knowledge about CSA among the school students. Respondents did not mention any specific program based on child sexual abuse and GTBT. They talked about the rape scene they saw in TV programs and movies. Some respondents mentioned crime based programs and crime news, which helped them to understand the concept of child sexual abuse. But these programs are not giving proper knowledge on the topics. It seems certain that the media has not produced any special program for child safety.

The media can bring a remarkable change in the attitude of society towards the sexual abuse of children in India. Children can access different media tools like Television, Radio, Newspaper, Magazines and Social Media, etc, so these media tools can be used to make them aware of child safety issues. In many countries media have run successful campaigns on child sexual abuse and they 
have succeeded in increasing the awareness of the topic in society. In India also some initiatives have been undertaken by the government through various modes of communication to disseminate information about children's rights but these were not sufficient to reach the target audience at large. Media should change their way of reporting the cases of child sexual abuse. Their responsibility should not be limited to just reporting the news, but also give an episodic coverage of news related to CSA without sensationalism. A well-focused mass media campaign can change people's attitudes towards the victims of child sexual abuse in society. There is also a need to conduct a feedback study of the program that will help them to develop more approachable programs for the target audiences and to make changes in the current programs if needed. It is felt that more such studies need to be conducted in different parts of the country to raise the awareness level of the students. There is a need to include such a subject in the school curriculum in a suitable manner to create the required awareness among students.

\section{REFERENCES}

[1] Agathis, N., Payne, C., \& Raphael, J. (2018). A "\#MeToo Movement" for Children: Increasing Awareness of Sexual Violence Against Children. Retrieved May 6, 2020, from https:/ / pediatrics. aappublications.org/content/142/2/e20180634

[2] Ahluwalia, H. (2018). Radio emerges as second most accessed media, outpaces social networking: Report. Retrieved December 20, 2019, from https:/ / www.livemint.com/Consumer/vBLB4xcdPUmEHCzafXUUoI/Radio-emerges-as-second-most-accessed-media-outpaces-social.html

[3] BBC News. (2017). India sexual abuse: 'Four child victims every hour'. Retrieved April 17, 2020, from https://www.bbc.com/news/world-asia-india-42193533

[4] Ganjapure, V. (2018). NCERT: Teachers asked to sensitize primary children on sexual abuse: Nagpur News - Times of India. Retrieved October 17, 2019, from https:/ / timesofindia.indiatimes.com/ city/nagpur/ncert-teachers-asked-to-sensitize-primary-children-on-sexual-abuse/articleshow /64101431.cms

[5] Gautam, R. (2020). Quattuor Minor Puer Factus Victim De Barbara Omne Hora In 2018: NCRB [Four Minors Became Victim of Barbarian Every Hour In 2018: NCRB]. Retrieved March 12, 2020, from https://hindi.gonewsindia.com/latest-news/news-and-politics/ cases-of-sexual-violence-against-minors-increase-ncrb-7930

[6] Goddard, C., \& Saunders, B. J. (2001). Child Abuse and the Media. Australian Institute of Family Studies, 14. Retrieved December 22, 2019, from https:/ / aifs.gov.au/cfca/ publications/ child-abuse-and-media

[7] India.com. (2018). Lack of Awareness \& Taboo Still Linger Amongst Indian Parents as Nation Fights For Protection of Children Against Sexual Exploitation. Retrieved November 15, 2019, from https://www.india.com/news/india/lack-of-awareness-taboo-still-linger-amongst-indianparents-as-nation-fights-for-protection-of-children-against-sexual-exploitation-3031491/

[8] India Internet 2019. (2019). Nielsen and Internet and Mobile Association of India 2019. Retrieved October 15, 2019, from https://cms.iamai.in/Content/ResearchPapers/d3654bcc-002f-4fc7ab39-e1fbeb00005d.pdf

[9] Kitzinger, J., \& Skidmore, P. (1995). Playing Safe: Media coverage of child sexual abuse prevention strategies. Child abuse review, 4(1), 47-56.

[10] Kumar, S. (2011). Child Sexual Abuse: A Comparative Study of Schools in Urban and Rural Areas in Tamil Nadu (Dissertation). Tirunelveli: Manonmaniam Uundaranar University India.

[11] Ministry of Women and Child Development. (2016-17). Annual Report 2016-17. Retrieved October 15, 2019, from https:// wcd.nic.in/sites/default/files/FINAL\%20WCD_AR_English\%20 2016-17.pdf 
[12] Nagasampige, K., \& Nagasampige, M. (2016). Effectiveness of newspaper in education (NIE) program on the student performance. Educational Quest: An Int. J. of Education and Applied Social Sciences, 7(1). doi: 10.5958/2230-7311.2016.00013.1

[13] National Commission for the Protection of Child Rights. (2016). National Workshop on Protection of Child Rights. Report 17th-18th December 2016. Retrieved December 15, 2019, from http:// ccpcr.technogs.com/uploads/media/report9.pdf

[14] National Commission for Protection of Child Rights. (2017). User Handbook on Protection of Children from Sexual Offences Act, 2012. Retrieved March 15, 2020, from https://ncpcr.gov.in/ showfile.php?lang=1\&level=1\&\&sublinkid=1289\&lid=1514pdf

[15] Parab, P. (2017). How a Chennai-based NGO is using Sarahah Against Child Sexual Abuse. Retrieved November 15, 2019, from http://gadgets.ndtv.com/culture/features/ sarahah-app-chennai-aware-ngo-child-sexual-abuse-1745791

[16] Qayyum, H. (2018). Media Coverage on Child Sexual Abuse in Developing Countries. International Journal of Scientific \& Engineering Research, 9(11), 1223-1229.

[17] Ramya, K. (2020). Most online content on child sexual abuse from India. The Hindu. Retrieved March 8, 2020, from https://www.thehindu.com/news/national/most-online-content-onchild-sexual-abuse-from-india/article31377784.ece

[18] Schramm, W. (1964). Mass media and national development. Stanford: Stanford University Press.

[19] Sengupta, N. (2020). 109 children sexually abused every day in India in 2018: NCRB. Retrieved February 17, 2020, from https://www.indiatoday.in/india/ story/109-children-sexually-abused-every-day-india-2018-1636160-2020-01-12

[20] The Hindu. (2011). Newspapers in the classroom. Retrieved December 22, 2019, from https:// www.thehindu.com/features/kids/newspapers-in-the-classroom/article2138727.ece

[21] The Print Team. (2019). As India falls 7 spots in global ranking, is it a safe country to raise children?. Retrieved March 17, 2020, from https://theprint.in/talk-point/ as-india-falls-7-spots-in-global-ranking-is-it-a-safe-country-to-raise-children/268417/

[22] Tom, D. (2020). Child abuse cases a cause for worry: Kochi News - Times of India. Retrieved April 15, 2020, from http://timesofindia.indiatimes.com/articleshow/74955890. cms?utm_source $=$ contentofinterest\&utm_medium $=$ text\&utm_campaign $=$ cppst

[23] UNICEF. (2013). Sexual Violence Against Children in the Caribbean: Report 2012. Retrieved December 18, 2019, from https://www.unicef.org/ECAO_Sexual_Violence_againstChildren_in_the_Caribbean.pdf

[24] Virani, P. (2000). Bitter chocolate - child sexual abuse in India. New York: Penguin Books Limited.

[25] Weatherred, J. (2015). Child Sexual Abuse and the Media: A Literature Review. Journal of Child Sexual Abuse, 24(1), 16-34. doi: 10.1080/10538712.2015.976302 